\title{
The Effects of Home-Based Literacy Activities on the Communication of Students with Severe Speech and Motor Impairments
}

\author{
Amy Swartz Cox \\ Denise M. Clark \\ Stacey N. Skoning \\ Theresa M. Wegner \\ Florence C. Muwana \\ University of Wisconsin Oshkosh
}

\begin{abstract}
This study examined the effects of using sensory, augmentative, and alternative communication (AAC), and supportive communication strategies on the rate and type of communication used by three students with severe speech and motor impairments (SSMI). Using a multiple baseline across behaviour design with sensory and AAC intervention phases, students were paired with a family member during shared reading activities using familiar and unfamiliar storybooks in their homes. All reading activities were video-recorded for analysis. Examination of recorded readings revealed that students demonstrated increases in their overall rates of communication. Further, these students successfully integrated communication devices into the reading process. The results suggest that students with severe disabilities can benefit from these forms of literacy strategies to increase their participation in reading tasks. Implications for research and practice are discussed.
\end{abstract}

Literacy skills have the power to dramatically affect the lives of students with severe disabilities. The benefits of literacy for this population include access to academics and learning environments, enhanced vocational options, increased independent living and quality of life, increased self-expression leading to friendships, and access to mainstream technology, such as the Internet that will allow them to overcome communication barriers 
(Browder, Mims, Spooner, Ahlgim-Delzell, \& Lee, 2008; Forts \& Luckasson, 2011; Light \& Kent-Walsh, 2003). Unfortunately, students with severe disabilities, including those with autism (Mirenda, 2003), severe intellectual disabilities, and severe speech and physical impairments (Erickson, Hanser, Hatch, \& Sanders, 2009; Kliewer, 2008; Kliewer \& Biklen, 2001; Ryndak, Morrison, \& Sommerstein, 1999) often are excluded from formal literacy instruction because parents and educators have low expectations and limited time to engage in reading activities (Erickson et al, 2009). Other educators acknowledge the need for literacy instruction, but focus on life skills instruction using word recognition and vocabulary of commonly occurring words students will encounter in their environments rather than focusing on higher literacy skills (Ruppar, Dymond, \& Gaffney, 2011).

To be successful, students with severe disabilities require literacy instruction that builds upon best-practice strategies utilized with students without disabilities, encourages meaningful participation in authentic literacy activities, and focuses on the cognitive processes supporting the development of reading and writing (Koppenhaver, 2000). Kliewer (2008) and others (Kliewer, Biklen, \& Kasa-Henderickson, 2006) posited that literacy is a civil right of all individuals, including those individuals with significant disabilities and encouraged professionals to raise their expectations of, and develop approaches for, increasing the literacy skills in students with significant disabilities so that they can become literate citizens. Examples of successful emergent literacy interventions leading to high literacy skills among young students with severe speech, motor, and intellectual impairments include literacy-rich environments, guided storybook reading, read alouds, independent exploration of reading and writing materials, and simple parent-child storybook reading interactions that foster emergent literacy and increased communication (Browder, Wood, Thompson, \& Ribuffo, 2014; Erickson et al., 2009; Koppenhaver, 2000; National Early Literacy Panel, 2008).

\section{Adult-Child Interactions}

Shared story reading is one evidence-based approach that promotes emergent literacy in children (National Early Literacy Panel, 2008) and is especially beneficial when used with students with moderate to severe disabilities (Hudson \& Test, 2011; Mims, Hudson, \& Browder, 2012). In this reading approach, readers provide opportunities through scaffolding (e.g., asking questions, modeling student responses, and expanding student responses) for the child to engage with and respond to reading material through repeated readings or repeated lines of the story, picture symbols, and AAC devices (Bellon-Harn \& Harn, 2008; Mims et al., 2012).

Several studies explored the usefulness of shared reading between parents and their children with significant disabilities, including those with SSMI. While investigating this reading activity, researchers noted increases in imitated language used by the child (Arnold, Lonigan, Whitehurst, \& Epstein, 1994), spontaneous expressive language use and vocabulary understanding (Kent-Walsh, Binger, \& Hasham, 2010; Soto \& Dukhovny, 2008), and increased student engagement (Kaderavek, Pentimonti, \& Justice, 2014). Specifically, Mims et al. (2012) found that using story read alouds, adapted biographies, and least intrusive prompts (wh-questions, rules for finding the wh- 
questions, and sequencing questions [first, next, and last]) increased listening comprehension, the number of correct responses, and generalization of these skills to new biographies in four middle-school students with intellectual disabilities and autism. Using a similar systematic prompting and questioning approach and shared story reading, Mims, Browder, Baker, Lee, and Spooner (2009) reported increased correct responses to comprehension questions from two students with significant intellectual disabilities and visual impairments. In addition, Browder et al. (2008) found that shared storybook reading employing universal-design-for-learning elements and systematic prompting increased the independent responses to questions by three young students with multiple disabilities and enhanced their engagement during reading activities. Finally, demonstrating the importance of reading on language development, McDonnell, FrielPatti, and Rollins (2003) studied the communication patterns that occurred between mothers and children without disabilities during repeated storybook readings. The researchers found that children's language use increased (e.g., self-initiated comments, answers to questions, and the number of different words they used) as they became more familiar with the stories read to them.

\section{Sensory Needs and Reading Readiness}

Physical, sensory, communicative, behavioural, or cognitive differences seen with many children with severe disabilities often hinder their learning (Koppenhaver, 2000; Leekam, Nieto, Libby, Wing, \& Gould, 2007). When these differences exist, occupational therapy researchers suggested that using strategies designed to meet students' underlying sensory needs can concomitantly increase their comfort level and improve attention, auditory and visual perception, coordination, and speech and language skills (Dunn, 2007; Kranowitz, 2003) prior to shared storybook reading activities.

Research literature is replete with accounts of sensory processing disorders in children with disabilities. While recent occupational therapy research primarily focuses on the sensory processing disorders of children - and to a lesser extent, adults - with autism (Bennett-Brown \& Dunn, 2010; Crane, Goddard, \& Pring, 2009; Hochhauser \& Engel-Yeger, 2010; Tomchek \& Dunn, 2007), similar deficits are observed in children with other disabilities (Olson \& Moulton, 2004). Likewise, there is research that supports sensory interventions that include the use of massage, rocking, and the use of fidgets, as well as alterations in visual and auditory stimuli in the environment (Chen \& BoggettCarsjens, 2005) and the use of weighted vests (Olson \& Moulton, 2004). Chen and Boggett-Carsjens (2005) reported on a child diagnosed with bipolar disorder, ADHD, oppositional defiant disorder, and non-verbal learning disability who exhibited explosive rages. After employing sensory interventions that included touch and pressure massages, rocking, the use of fidgets, and adjustments to the environment to limit visual and auditory overexposure, their client was calmer, alert, and focused, and he was able to return to his general education classroom to complete the school year. Olson and Moulton (2004) surveyed 51 pediatric occupational therapists about the effectiveness of using weighted vests in altering behaviours in children with developmental disorders, namely autism, attention deficit hyperactivity disorder, and sensory integration dysfunction. Occupational therapists reported a significant reduction in children's behaviours of rocking, hitting, and temper tantrums, accompanied by increases in eye contact, attention, and staying on task. 
Researchers also recommended that adults provide opportunities for children to actively control portions of the reading process by allowing them to help prepare for reading activities and make simple choices about the books being read and where reading occurs (Koppenhaver \& Pierce, 1994; Light, Binger, \& Kelford Smith, 1994).

\section{AAC and Reading Materials}

Recognizing the importance of emergent literacy acquisition for students with severe disabilities who use AAC, research has grown to include both children and youth (Browder et al., 2014; Kent-Walsh et al., 2010; Ogletree, Bruce, Finch, Fahley, \& McClean, 2010; Soto \& Dukhovny, 2008). Browder et al. (2014) listed the use of AAC as one evidence-based practice used to increase the literacy skills in students with severe disabilities. Soto and Dukhovny (2008) reported the gains in the one-word and multipleword utterances used by one child in response to shared book reading activities and communication strategies paired with the use of AAC. In another study, a group of six parents effectively used communication strategies during shared book reading tasks to increase the communication of children who used AAC (Kent-Walsh et al., 2010). Skotko, Koppenhaver, and Erickson (2004) examined the communication of three girls with Rett syndrome while reading stories with their mothers. During successive phases of their multiple baseline intervention study, the researchers found that the use of interaction-building strategies, AAC, and assistive technology devices increased the girls' quantity of communication attempts and the types of interactions they used. Similarly, Liboiron and Soto (2006) demonstrated increased frequency and semantic complexity of utterances made by a student who used AAC and an adult practitioner during shared story readings in which scaffolding strategies were used, including asking comprehension questions, cueing, pointing and gesturing, and using print references.

In addition to the use of AAC during shared storybook reading, using ageappropriate materials has been advocated more recently (Browder, Hudson, \& Wood, 2013; Browder, Trela, \& Jimenez, 2007; Mims et al., 2012; Morgan \& Moni, 2008; Shurr \& Taber-Doughty, 2012) as a means of providing rich literacy opportunities for older students with significant disabilities. Shurr and Taber-Doughty (2012) demonstrated the gains made in comprehension by middle-school students with moderate intellectual disabilities when age-appropriate, short expository, high interest reading material was paired with picture symbols and questioning strategies during read-aloud sessions. Other researchers confirmed the effectiveness of using age-appropriate adapted books and novels to increase the comprehension, vocabulary, and book-awareness skills of middleschool students with moderate to severe intellectual disabilities (Browder et al., 2013; Browder et al., 2007). Mims et al. (2012) used age-appropriate adapted biographies and systematic prompting strategies during read alouds, and demonstrated increases in comprehension in four middle-school students with intellectual disabilities and autism.

Past studies have focused on a number of book qualities - also adopted for this present study - that support reading-based communication interactions, such as a small number of words per page, large print, repeated or redundant words in the text (Justice \& Kaderavek, 2002), repeated lines (Koppenhaver, Erickson, \& Skotko, 2001), and book familiarity (McDonell et al., 2003). Bellon and Ogletree (2000) recommended using 
books that are attractive, with pertinent illustrations, and that include predictable language structures and topics relevant to the child's life experiences or daily routine. In addition, books should be complicated enough to teach the child something new while describing a sequence of events, the unexpected results of an action or cause-effect relationships or goal behaviour (Bellon \& Ogletree, 2000; Bellon, Ogletree, \& Harn, 2000), yet not so sophisticated as to hinder his or her interaction. These recommendations also find support in the literature relating to students with disabilities who use AAC (Musselwhite \& King-DeBaun, 1997).

\section{Purpose of the Current Study}

Several researchers identified the need for additional studies regarding literacy instruction for students with significant disabilities (Browder, Lee, \& Mims, 2011; Browder, Wakeman, Spooner, Ahlgrim-Delzell, \& Algozzine, 2006; Mims et al., 2012; Skotko et al., 2004). The purpose of this study was to examine the use of sensory, AAC, and supportive communication strategies on the rate and type of responses used by three students with SSMI during shared reading tasks. Our study followed the methods previously employed by Bedrosian (1999), Koppenhaver, Erickson, and Skotko (2001), and Light et al. (1994) to investigate whether shared reading methods typically employed with younger students could benefit older students with SSMI. Through a multiple baseline across behaviour design, we attempted to answer the following research questions:

1. Does the use of sensory and control-based calming procedures prior to reading increase the rate and type of student communication during shared reading?

2. Does the use of AAC and supportive communication strategies during shared reading with caregivers increase the rate and type of student communication?

\section{Method}

\section{Participants}

Students. We recognized the difficulty in finding a homogenous sample among the population of children and adolescents with significant disabilities and the corresponding importance of controlling the subject selection process to promote accurate analysis and generalization of the results (Bedrosian, 1999; Higginbotham \& Bedrosian, 1995). For this reason, students participating in the study met several pre-established criteria.

All students involved in this study lived in a north-central state in the United States and attended schools in the same school district, but none attended the same school. Students selected were in elementary through middle school and were all in the emergent stage of literacy; meaning they enjoyed looking at, manipulating, or listening to picture books, but they had difficulty communicating or participating during reading activities. None of the students chosen for this home-based study had school-based literacy instruction or literacy goals as part of their individualized education programs (IEP). These students also had physical or motor impairments including difficulties with motor planning, apraxia, and sensory processing with varying etiologies, but they did not have 
visual or auditory problems that impacted their listening to storybooks and attending to illustrations and communication symbols.

The research sample included three students: Adam, Patrick, and Timothy (pseudonyms). All participants were White. Students' ages ranged from 7 to 13, and their diagnosed disabilities varied. The public school system that they attended considered all of the students to have severe intellectual disabilities. Because of their disabilities, all students were unable to communicate effectively, especially when the referent was abstract or inaccessible. Table 1 provides the educational, communication, and physical characteristics of each student.

\section{Table 1}

\section{Student Characteristics}

\begin{tabular}{|c|c|c|c|}
\hline $\begin{array}{l}\text { Student } \\
\text { (Age, } \\
\text { Gender) }\end{array}$ & $\begin{array}{l}\text { Educational } \\
\text { Placement }\end{array}$ & Communication Modes & Physical Description \\
\hline $\begin{array}{l}\text { Adam } \\
(13, \mathrm{M})\end{array}$ & $\begin{array}{l}\text { Self-contained, } \\
\text { ID-S, } \\
\text { middle school }\end{array}$ & $\begin{array}{l}\text { Gestures, modified } \\
\text { signs, pointing and } \\
\text { leading, PECS, simple } \\
\text { AAC, facial expression }\end{array}$ & $\begin{array}{l}\text { Ambulatory; difficulties with motor planning } \\
\text { and apraxia; easily distracted; sought toys or } \\
\text { other objects to hold and spin; required } \\
\text { constant supervision }\end{array}$ \\
\hline $\begin{array}{l}\text { Patrick } \\
(12, \mathrm{M})\end{array}$ & $\begin{array}{l}\text { Self-contained, } \\
\text { ID-S, elementary } \\
\text { school }\end{array}$ & $\begin{array}{l}\text { Gestures, sounds, } \\
\text { leading, demonstrating }\end{array}$ & $\begin{array}{l}\text { Ambulatory; resisted activities; spun rolled } \\
\text { magazines, books, and cups; required } \\
\text { constant supervision }\end{array}$ \\
\hline $\begin{array}{l}\text { Timothy } \\
(7, \mathrm{M})\end{array}$ & $\begin{array}{l}\text { Self-contained, } \\
\text { ID-S, elementary } \\
\text { school }\end{array}$ & $\begin{array}{l}\text { Limited AAC, behaviour, } \\
\text { facial expression, } \\
\text { vocalizations ("coos") }\end{array}$ & $\begin{array}{l}\text { Significant physical limitations; limited control } \\
\text { of body movements; difficult to understand } \\
\text { communication; required pervasive support }\end{array}$ \\
\hline
\end{tabular}

Note: ID-S, intellectual disabilities—severe; PECS, picture exchange communication system.

Adult readers. We paired students with a parent to form a reading dyad. The adult members of the dyad were at least 20 years of age and, prior to the study, regularly read with the student in their home environments.

The adult readers possessed varying levels of training prior to beginning the study. Adams's father attended workshops and classes in regular and special education, reading, and sensory integration, and observed Adam's therapies. Patrick's mother attended workshops and read articles and books on special education and communication; she, too, observed her son's therapies. Timothy's mother did not report being involved in additional training aside from observing his therapies.

\section{Procedures}

This study used a single-subject, multiple baseline across behaviour design (Koppenhaver, Erickson, \& Skotko., 2001) to examine the use of shared reading, AAC, sensory and control-based calming, and supportive communication approaches on the students' rate of communication. This design permitted us to examine the combined effects of a two-part treatment program: One part included the use of sensory and calming techniques to prepare the student for the reading task; and the other, the use of $\mathrm{AAC}$ and supportive communication approaches during reading activities that were 
modeled after studies developed by Bedrosian (1999), Koppenhaver, Erickson, and Skotko (2001), and Light et al. (1994). The three phases of this study included baseline (phase 1), sensory intervention (phase 2), and AAC intervention (phase 3).

Baseline. For the first phase of the study, we collected baseline data from each of the adult reader and student reading sessions. This phase provided us with evidence of the typical behaviours used by the adult readers and the students during reading activities. We were especially interested in the students' rate and type of communication used during these reading sessions.

The dyads selected two books for the baseline period and a book bag for storing study materials. The adult readers chose one of the books to video record each week for a two-week period. The adult readers received no specific directions regarding strategies to use during baseline readings; rather, they followed their own pre-established reading routines. Further, we encouraged the dyads to read each book as often as they liked, noting the total number of readings on a tally sheet. We informed the adult readers of the staggered treatment schedule involved in multiple-baseline designs and provided an estimate of when the first treatment would begin.

Training. Prior to implementing each of the two intervention phases, we conducted a formal training session at a local university for the adult readers to learn the sensory, calming, AAC, and communication approaches used in the study. In each training session, we modeled the sensory and calming strategies (snuggling, massage, rocking, hugging, and providing fidget toys) and the AAC and communication approaches (voice output devices, picture symbols, page fluffers, repeated readings, questioning, and allowing wait time). For reference, the adult readers were provided with written summaries of the strategies for each intervention phase, and they were taught how to video record each reading session. All video recordings were analyzed for accurate implementation of the intervention, and adult readers were provided with feedback if adjustments to their approaches using the strategies were necessary.

Sensory intervention. Intervention during this phase encouraged the adult readers to use calming procedures (e.g., snuggling with blankets, playing background music, rocking, hugging, or massaging the student), decrease their own autonomy during shared reading, and promote adult-student collaboration. Based upon observations of video recorded reading interactions in the baseline and sensory intervention phase, we also made suggestions regarding the students' positioning, choice of reading environments, fidelity of the execution of sensory and calming strategies, and techniques for minimizing distractions. In all cases, the instructions purposefully excluded communication-specific issues including the use of AAC.

In addition to these procedures, the adult readers were given one trade book and one adapted book that they previously chose based on student interest and ageappropriateness. They selected one additional book to complete the required three readings and video recordings each week for four weeks.

AAC intervention. After a training period in the use of AAC materials and supportive communication approaches to encourage student involvement in the reading sessions, adult readers and students utilized them in the final, approximately four-week- 
long AAC intervention phase. Specifically, we provided a collection of AAC materials tailored to the students' specific needs, including picture symbols, choice of one trade and one adapted book, and voice-output communication devices (Table 2). Adult readers also received a small keychain flashlight to attract the student's attention to important elements in the story (illustrations or words) by directing its beam to specific items on a book's page.

\section{Table 2}

\section{Voice Output Augmentative and} Alternative Communication Devices Used by Students

\begin{tabular}{lll}
\hline Student & $\begin{array}{l}\text { Single Message Device } \\
\text { (Manufacturer) }\end{array}$ & $\begin{array}{l}\text { Multiple Message Device } \\
\text { (Manufacturer) }\end{array}$ \\
\hline Adam & $\begin{array}{l}\text { One Step Communicator } \\
\text { (AbleNet) }\end{array}$ & $\begin{array}{l}\text { Go Talk } \\
\text { (Attainment Company) }\end{array}$ \\
Patrick & $\begin{array}{l}\text { Cheap Talk 8 } \\
\text { (Enabling Devices) }\end{array}$ & $\begin{array}{l}\text { Step-by-Step Communicator } \\
\text { (AbleNet) }\end{array}$ \\
Timothy & $\begin{array}{l}\text { BigMack } \\
\text { (AbleNet) }\end{array}$ & $\begin{array}{l}\text { Cheap Talk 8 } \\
\text { (Enabling Devices) }\end{array}$ \\
\hline
\end{tabular}

We provided each adult reader with a list of supportive communication approaches modeled after those outlined by Skotko et al. (2004) and Light et al. (1994). The adult readers were encouraged to: assume meaningfulness of students' communication attempts; prompt the use of communication devices or symbols through natural questions and comments; pause during reading to allow student to process and communicate; talk about the story and how it relates the student; encourage repeated readings of favorite texts, allowing students to gradually take a more active role in the reading process; ask highly evocative questions that encourage students to infer, predict, or interpret; and provide useful, effective vocabulary to maximize the use of symbols and voice-output devices. In addition, we encouraged the adult readers to use a modified cloze procedure in which the adult verbally stated a partial phrase pertinent to the story, and offered opportunities for the students to complete the phrase with the desired word through vocalizations or physical movements (e.g., pointing, gesturing, eye pointing, or manual signing).

The adult readers were encouraged to continue to use approaches from the sensory intervention phase in combination with the AAC materials and devices as they read each new study book and one book of their choice once per week for four weeks. Again, we asked the readers to video record each new book in addition to one reading of a dyadselected book once a week for the four-week period. Once the AAC intervention video recordings were reviewed, we made suggestions to the adult readers for the proper execution of the strategies to ensure fidelity of the intervention.

Materials. Recognizing the diverse interests, preferences, and needs of students of various ages, we specifically attempted to assemble a collection of books among which any participant might find several appealing titles. Accordingly, the collection included illustrations and storylines appropriate for elementary through high school aged students and relevant subject matter. These books also included short text and repeated lines or rhyming words. To assure that everyone found personally interesting books, both 
categories featured a wide variety of topics and formats (Tables 3 and 4). The participants chose from 45 books, both trade and adapted, that we selected based on recommendations from previous studies (Bellon et al., 2000; Justice \& Kaderavek, 2002; Koppenhaver, Erickson, \& Skotko, 2001; Musselwhite \& King-DeBaun, 1997) for the sensory and AAC intervention phases of the study.

Table 3

\section{List of Selected Trade Books Used in the Study}

\begin{tabular}{|c|c|c|}
\hline Author(s), (Date) & Title & Publisher \\
\hline $\begin{array}{l}\text { Ayleswork, J., \& Gammell, S. } \\
\text { (1992) }\end{array}$ & Old Black Fly & $\begin{array}{l}\text { Henry Holt and Co. } \\
\text { New York, NY }\end{array}$ \\
\hline $\begin{array}{l}\text { Cole, J., \& Alley, R. W. } \\
\text { (1989) }\end{array}$ & Who Put the Pepper in the Pot? & $\begin{array}{l}\text { Parents Magazine Press } \\
\text { Cambridge, MA }\end{array}$ \\
\hline $\begin{array}{l}\text { Dabcovich, L. } \\
\text { (1982) }\end{array}$ & Sleepy Bear & $\begin{array}{l}\text { E. P. Dutton. } \\
\text { New York, NY }\end{array}$ \\
\hline $\begin{array}{l}\text { Hall, K., \& Rader, L. } \\
\text { (1995) }\end{array}$ & A Bad, Bad Day & $\begin{array}{l}\text { Scholastic. } \\
\text { New York, NY }\end{array}$ \\
\hline $\begin{array}{l}\text { Hindley, J., \& Benedict, W. } \\
\text { (1995) }\end{array}$ & The Big Red Bus & $\begin{array}{l}\text { Candlewick Press. } \\
\text { Cambridge, MA }\end{array}$ \\
\hline $\begin{array}{l}\text { Krensky, S., \& Mathieu, J. } \\
\text { (2001) }\end{array}$ & What a Mess! & $\begin{array}{l}\text { Random House. } \\
\text { New York, NY }\end{array}$ \\
\hline $\begin{array}{l}\text { Robart, R., \& Kovalski, M. } \\
\text { (1986) }\end{array}$ & The Cake That Mack Ate & $\begin{array}{l}\text { Little, Brown, and Co. } \\
\text { Boston, MA }\end{array}$ \\
\hline $\begin{array}{l}\text { Sherman, A., \& Busch, L. } \\
\text { (2004) }\end{array}$ & $\begin{array}{l}\text { Hello Muddah, Hello Faddah! A Letter } \\
\text { from Camp }\end{array}$ & $\begin{array}{l}\text { Dutton Children's Books. } \\
\text { New York, NY }\end{array}$ \\
\hline $\begin{array}{l}\text { Viorst, J., \& Glasser, R.P. } \\
\text { (1995) }\end{array}$ & $\begin{array}{l}\text { Who's Not (Do you hear me? I mean it!) } \\
\text { Going to Move }\end{array}$ & $\begin{array}{l}\text { Scholastic. } \\
\text { New York, NY }\end{array}$ \\
\hline $\begin{array}{l}\text { Yolen, J., \& Schoenherr, J. } \\
\text { (1987) }\end{array}$ & Owl Moon & $\begin{array}{l}\text { Philomel Books. } \\
\text { New York, NY }\end{array}$ \\
\hline
\end{tabular}

Table 4

List of Selected Adapted Books Used in the Study

\begin{tabular}{|c|c|c|}
\hline Author & Title & Publisher \\
\hline $\begin{array}{l}\text { King-DeBaun, } P \text {. } \\
(1990)\end{array}$ & Storytime & $\begin{array}{l}\text { Creative Communicating. } \\
\text { Park City, UT }\end{array}$ \\
\hline $\begin{array}{l}\text { King-DeBaun, P. } \\
\text { (1992) }\end{array}$ & Storytime Supplement & $\begin{array}{l}\text { Creative Communicating. } \\
\text { Park City, UT }\end{array}$ \\
\hline $\begin{array}{l}\text { King-DeBaun, } P \text {. } \\
(1990)\end{array}$ & Storytime Just for Fun & $\begin{array}{l}\text { Creative Communicating. } \\
\text { Park City, UT }\end{array}$ \\
\hline $\begin{array}{l}\text { King-DeBaun, P. } \\
(1990)\end{array}$ & Storytime Holiday Fun & $\begin{array}{l}\text { Creative Communicating. } \\
\text { Park City, UT }\end{array}$ \\
\hline $\begin{array}{l}\text { Musselwhite, C. R. } \\
\text { (1993) }\end{array}$ & $\begin{array}{l}\text { RAPS: Reading Activities } \\
\text { Project for Older Students }\end{array}$ & $\begin{array}{l}\text { Southwest Human Development, Inc. } \\
\text { Phoenix, AZ }\end{array}$ \\
\hline
\end{tabular}


To create adapted books, we selected age-appropriate stories from P. DeBraun and C. R. Musselwhite's published collections designed for use by learners who communicate with AAC (Table 4). From these selections, we hand coloured the illustrations, laminated, and bound the texts to make durable student books. In a few cases, the team substituted photographic illustrations or clip art in place of the provided pictures to make the texts more suitable for older readers. The trade books used in this study were not adapted in any way.

We provided the participants with Sony Digital Video Cameras (model DCR-TRV 20) and corresponding videocassettes that were later converted into digital videodiscs for coding and analysis. Participants also received tripods to hold the video cameras for recording the reading sessions.

\section{Data Collection}

We instructed the adult readers to video record each reading session with the camera located not directly in front of the reading location but at approximately $45^{\circ}$, and approximately 2.5 to 3.0 metres away. The adults were instructed to ensure that the students' eyes and whole body, as well as the adult reader were present in the video recording. This allowed us to see the students' nonverbal communication, including gestures and glances, when they reviewed the recordings. Adult readers used one tape per week for the recordings, and labeled them with the dates in which the readings occurred. Once the baseline phase was complete, the adult readers returned the video recordings either through direct contact with a member of the research team or using postage-paid envelopes.

\section{Coding and Data Analysis}

We examined the behaviour each student used to communicate interest, exert control, or make choices during the video recorded portion of the reading sessions, following a basic protocol and coding system modified from those used by Skotko, Koppenhaver, and Erickson (2003a; 2003b) and Light et al. (1994). The coded behaviours included the students' manipulation of the book (MB), vocalizations (V), eye pointing (EP), pointing or gesturing (PG), manual signing (MS), augmentative and alternate communication (AAC), and manipulation of other books or objects that were not related to the study $(\mathrm{OBO})$.

The principal researcher and a research assistant reviewed and coded the interactions documented in the video recordings of the reading dyads. The research assistant was unaware of the purpose of the study, and at scheduled times throughout coding process, the data collected by the researcher and research assistant were compared to ensure .80 agreement for reliability. In all the data collected, inter-observer agreement was above .80 .

To assure accuracy and inter-observer agreement, a third researcher separately reviewed a random sample of $20 \%$ of all readings from each dyad. This sample included one reading from baseline and two each from the other phases. Overall the third researcher reviewed 20 videotaped reading interactions. After studying a written copy of the coding definitions and discussing protocol with the principal researcher, this 
researcher made two attempts at coding each tape, with the second to assure accuracy. Subsequent comparison and discussion focused on disagreements and omissions until a $100 \%$ level of agreement or consensus was reached. Consensus was achieved using one of three options: A behaviour could be included or excluded after discussion, or a new category could be created. Statistical analysis examined frequencies and types of interactions between members of the dyad.

To determine whether the sensory intervention or AAC intervention influenced the rate of student communication during reading interactions, we first looked at all identified behaviours combined, then assessed students' use of individual types of behaviours. As a result, we were able to examine general trends while isolating each student's primary modes of communication across the study phases. Converting raw data into frequencies facilitated all comparisons among the students. To address the saliency of AAC, we compared the students' overall rate for all communication modes used with their rate for AAC.

\section{Results}

We analyzed a total of 79 readings (baseline: 18; sensory intervention: 27; AAC intervention: 34 ) spanning 4.15 hours of videotape. Table 5 summarizes the number of readings and length of readings for each dyad pair for the baseline, sensory intervention, and AAC intervention phases. For each reading dyad, the length of shared storybook readings varied greatly from day to day throughout all phases of the study (Table 6). While many of the variables leading to the range of reading lengths could not be determined, the videotapes documented several potential contributing factors, including student fatigue, attention difficulties, and external distractions. Notably, Patrick's length of readings increased steadily over the course of the study. We asked the dyads to read twelve books in each of the intervention phases; however, no dyad completed this requirement. In most cases, adult-readers reported that health problems, family scheduling, work, or travel limited the amount of time available for reading.

\section{Baseline and Sensory Intervention}

During baseline and sensory intervention phases, students used only pre-existing forms of communication. For Adam this meant that most communication attempts in the initial study phases involved pointing and gesturing, manipulating the book or other books or objects, and vocalizations. The rates at which Adam preformed these behaviours totaled 4.03 occurrences per minute for baseline and 7.12 per minute for the sensory intervention phase. Specific sensory and calming strategies used with Adam included a weighted blanket and a weighted vest. Patrick relied heavily on vocalizing and manipulating the book. In reviewing Patrick's videotapes, these behaviours were observed at a decreasing rate of 7.80 and 6.38 occurrences per minute in baseline and in the sensory intervention phases, respectively. Sensory and calming strategies used with Patrick included fidgets (rolled magazine or a cup of pasta that he held). For both students, vocalizations and manipulating the book were the only communication behaviours that occurred more than once every minute in at least one of the first two study phases. Overall, Adam and Patrick displayed the broadest array of communication 
types, demonstrating use of all coded varieties multiple times over the course of the study, with vocalizations and pointing and gesturing being the most prominent.

Table 5

Number and Length of Readings for Individual Dyads Across Study Phases

\begin{tabular}{cccc}
\hline Phase & $\begin{array}{c}\text { Number of } \\
\text { readings }\end{array}$ & $\begin{array}{c}\text { Average } \\
\text { length of } \\
\text { reading (min) }\end{array}$ & $\begin{array}{c}\text { Range of the total } \\
\text { reading time (min) }\end{array}$ \\
\hline Adam & 6 & 3.48 & 1.68 to 5.23 \\
Baseline & 10 & 2.61 & 1.23 to 5.06 \\
Phase 2 & 12 & 2.57 & 1.37 to 3.13 \\
Phase 3 & & & \\
Patrick & 6 & 2.40 & 1.25 to 3.43 \\
Baseline & 10 & 3.37 & 1.12 to 5.15 \\
Phase 2 & 8 & 4.51 & 1.00 to 7.28 \\
Phase 3 & & & \\
Timothy & 6 & 3.48 & 1.48 to 6.72 \\
Baseline & 7 & 4.04 & 1.05 to 7.33 \\
Phase 2 & 12 & 3.22 & 1.20 to 6.17 \\
Phase 3 & 6 to 12 & 2.40 to 4.51 & 1.00 to 7.33 \\
\hline Range & &
\end{tabular}

Table 6

Number and Length of Readings for All Dyads Across Study Phases

\begin{tabular}{lccc}
\hline Phase & $\begin{array}{c}\text { Number of } \\
\text { Readings }\end{array}$ & $\begin{array}{c}\text { Range of the } \\
\text { length of } \\
\text { readings (min) }\end{array}$ & $\begin{array}{c}\text { Range of the total } \\
\text { reading } \\
\text { times (min) }\end{array}$ \\
\hline Baseline & 6 & 1.25 to 6.72 & 13.47 to 20.90 \\
Phase 2 & 7 to 12 & 0.75 to 7.33 & 26.13 to 33.68 \\
Phase 3 & 4 to 12 & 1.00 to 7.17 & 11.28 to 38.58 \\
Total & 22 to 28 & 0.75 to 7.33 & 53.75 to 87.75 \\
\hline
\end{tabular}

Sensory and calming strategies used with Timothy consisted of joint compression and a weighted blanket. Data analysis revealed that Timothy's behaviour and communication during baseline and sensory intervention consisted solely of eye pointing to elements in the book, gesturing, and manipulating the book. Of these, only eye pointing occurred more often than once every two minutes (1.34 occurrences per minute). 
The communication acts coded as points or gestures did not actually include pointing. Rather, they were two instances when Timothy responded to his mother's request to raise his head and three others when he lowered his arms on command. We considered these behaviours intentional because, despite his difficulty controlling body movements, the relationship between the requests and actions were clearly evident when viewing the video recording. Similarly, Timothy manipulated the book when he bumped it with his hand after being asked to close it (Figures 1 and 2).

\section{AAC Intervention}

Devices to aide in communication, including voice output AAC (see Table 2), picture symbols, and page fluffers were provided to the dyads in the final study phase. To examine the effectiveness of their use, we compared each student's rate of AAC usage to the rate of all other types of behaviour and communication. Immediately upon entering this intervention phase, all readers quickly began using AAC. Adam and Patrick demonstrated slight to moderate decreases in their use of other forms of communication coinciding with their initiation of AAC use. During the reading of two non-study books, Adam's father did not directly provide him access to AAC, yet even in these readings, he independently sought a device and used it minimally. Patrick's use of AAC never outpaced his communication by other means, and in fact, he increased his use of vocalizations and pointing and gesturing in the sensory and AAC phases of the study. Though Patrick used more types of communication behaviours in the intervention phases of the study compared to his baseline behaviours, his total number of communication behaviours actually decreased from baseline in the intervention phases. Timothy, on the other hand, relied almost completely on the use of AAC during this intervention phase.

\section{Discussion}

This study sought to examine the use of sensory, AAC, and supportive communication strategies on the rate and type of communication responses used by three students with SSMI during shared reading tasks. The analysis of the data revealed encouraging trends in the rates of communication of students, suggesting that even students with severe disabilities benefit from shared storybook reading. While the present study focused on somewhat different variables, the results appeared similar to the findings of other researchers (Browder et al., 2008; Kaderavek et al., 2014; Kent-Walsh et al., 2010; Koppenhaver, Erickson, Harris, et al., 2001; Koppenhaver, Erickson, \& Skotko, 2001; Skotko et al., 2004; Soto \& Dukhovny, 2008) who documented increased communication behaviours used by children and youth with significant disabilities as the result of using AAC during shared storybook-reading sessions. 
Figure 1. Students' Rate of Behaviour and Communication by Type
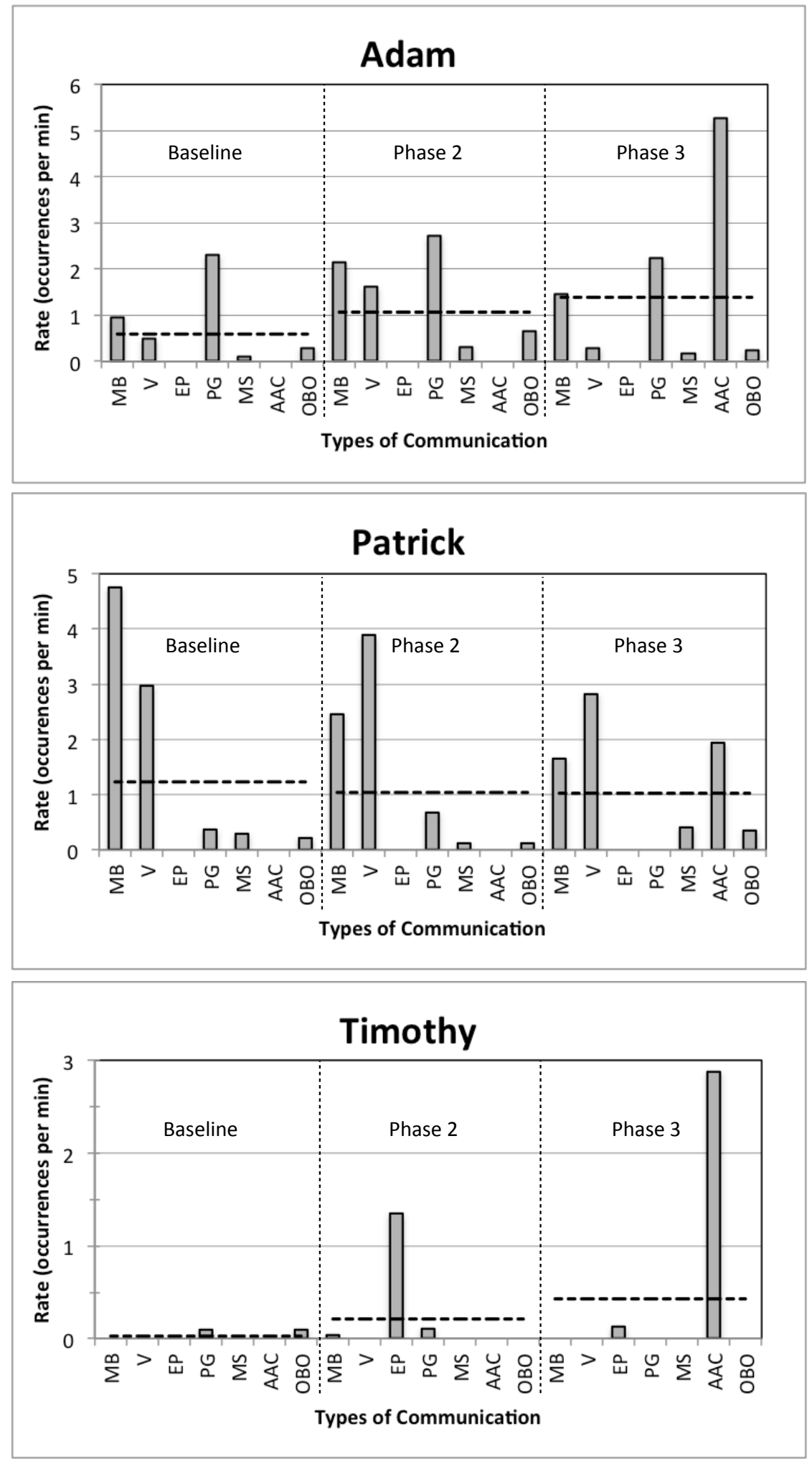

$M B$, manipulation of the book; $V$, vocalizations; EP, eye pointing; PG, pointing or gesturing; MS, manual signing; $A A C$, augmentative and alternate communication; $\mathrm{OBO}$, manipulation of other books or objects that were not related to the study. Dashed lines for each phase represent the average rate across all behaviours. 
Figure 2. Overall Rate of Communicative Behaviours Across Phases
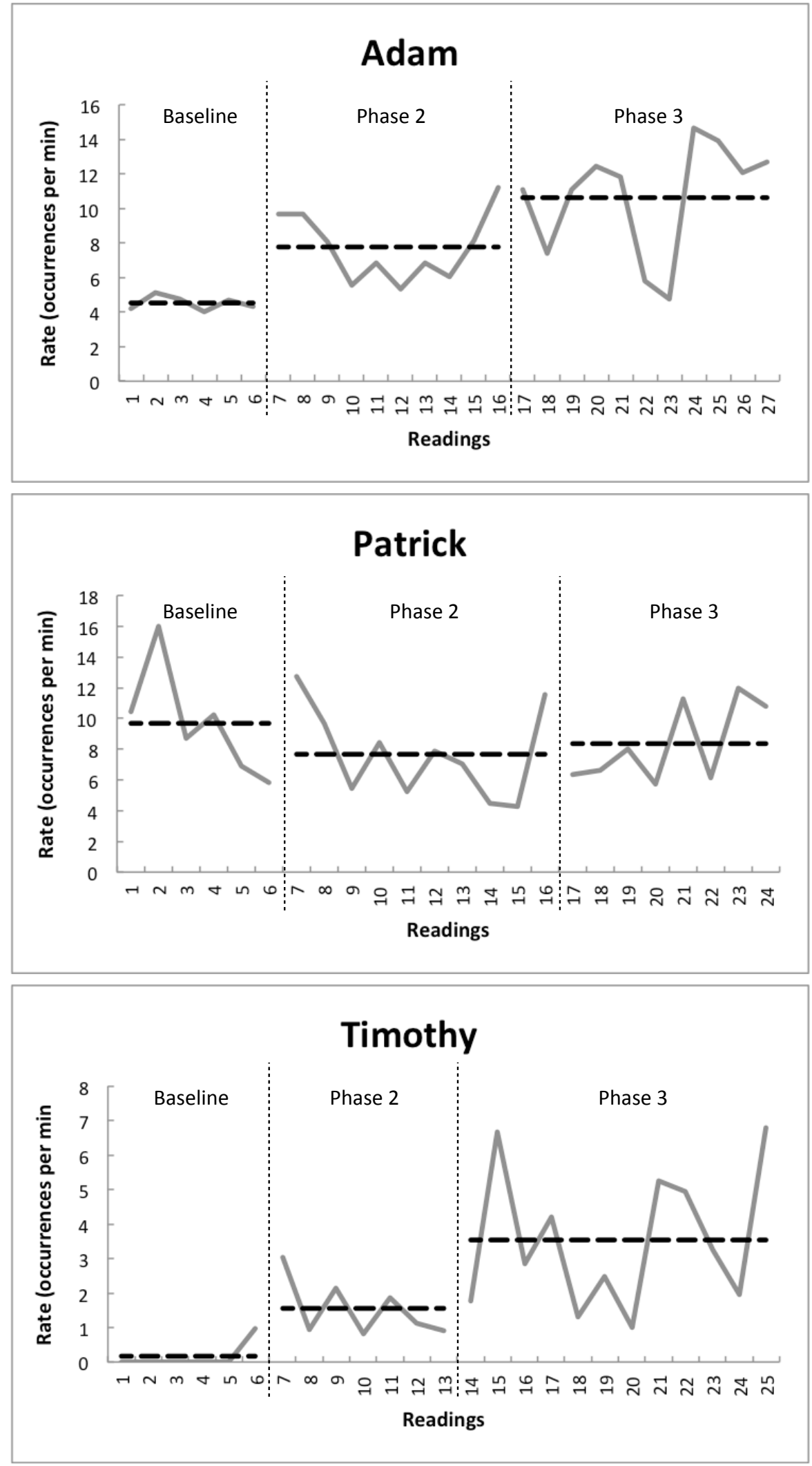

Dashed lines for each phase represent the average rate across all behaviours. 


\section{Sensory and AAC Results}

Considering the results of the present study, we could not ascertain how much of the improvements in students' rates of behaviour and communication during the sensory intervention phase related directly to the sensory and control-based calming intervention. Other factors, including increased opportunities for reading sessions as well as changes in adults' level of confidence, familiarity with the process, and perceptions of students' communication also may have influenced student success. In their work, Koppenhaver, Erickson, and Skotko (2001) provided similar suggestions of causality. However, the potential value of the interventions utilized should not be discounted. To better determine the effectiveness of the sensory interventions used in this study, future research should focus on a crossover design in which additional phases are introduced with each phase focusing on a single sensory or calming intervention at a time.

Data from the AAC intervention phase appeared more conclusive. Immediately following the provision of (AAC) materials and adult reader training, all students achieved relatively high rates of AAC use regardless of the book types being read (trade or adapted). In general, Adam and Patrick, who used multiple modes of communication prior to the study, during video recorded readings appeared to communicate more frequently than Timothy, who used fewer modes of communication. Additionally, Adam and Patrick were better at maintaining the use of other forms of communication after the introduction of AAC. The results of this study highlight the importance of ACC in building emergent literacy skills (Light \& Kent-Walsh, 2003); however, it appears that currently, students who use AAC rarely develop adequate language and communication skills to support more complex forms of literacy learning (Sturm, 2003). As literacy is based on communication, it seems that students' opportunity to acquire later developing conventional literacy skills hinge on the quality and effectiveness of their AAC-based access tools (Sturm \& Clendon, 2004) and their communication skills balanced with the provision of ample amounts of effectively managed instructional time. Perhaps, the results of this study may generate additional investigations of AAC use as a means of increasing student communication and engagement during shared storybook reading, expanding on this study to include emergent literacy skills and higher forms of literacy development.

\section{Rate and Type of Communication}

We were encouraged by the general upward trends in two of the students' communication. For example, Timothy demonstrated promising improvements in communication as the study progressed. However, the current study lacked measures to determine if his gains and those of the other students related to the interventions, increased opportunity, or other factors. Therefore, future research should again focus on a crossover design in which additional phases are introduced, with each phase focusing on a single AAC intervention at a time, such as adaptations to books being read, the use of adult reader questioning techniques, and the use of voice output devices.

Timothy began the study as primarily a non-communicator in reading situations, but during the sensory and AAC phases of this study, his communication attempts did indeed increase. In Patrick's case, however, his communication occurrences actually decreased in both intervention phases of the study. The increase in the variety of communicative 
behaviours demonstrated by Adam and Patrick is striking, as is Timothy's increased use of AAC once the interventions were introduced.

While shared storybook reading has the potential to improve students' communication, it remains the first step. For all of the students, including Timothy, improvement in communication during reading remains insufficient for meeting daily needs and improving quality of life. For continued improvement, dyad members must learn to apply these skills in other situations. Those individuals interested in truly improving the lives of students like Timothy must find ways to move students beyond early communication and emergent literacy skills, toward advanced communication, literacy, and more effective and diverse applications of these tools.

Patrick also made great gains in his attention to the book and communication. Patrick's early reading sessions depicted a resistant student who often began readings by performing the avoidance or self-injurious behaviours he often employed elsewhere. Fortunately, occurrences of these behaviours rapidly decreased. By the end of the study, Patrick remained focused for extended periods, pointed at elements in the text, and seemed to enjoy reading with his mother. Repeated practice, patience, and persistence seemed to have given him the opportunity to succeed. The same traits were apparent in the readings of the other dyads as well. Other researchers wishing to replicate Patrick's success should consider these dynamics.

The results suggest that all of the students in this study, regardless of their perceived level of ability, could benefit from some form of emergent literacy instruction. This becomes especially important when considering the goals and objectives commonly found on students' IEPs and their daily home and school routines. The fact that no student in the study received emergent literacy or literacy instruction in the school setting confirms this, and suggests that parents often view their child as incapable, believe they have little power to affect change, or feel they lack the knowledge required to promote their child's communication development.

\section{Limitations}

Inherently, much of the research involving individuals with severe disabilities has limitations related to the diversity of the population. The range of ages and student characteristics present in the current study also restricts generalization of the results. Therefore, the patterns of communication observed when Adam, Patrick, and Timothy followed study procedures and read with an adult may not be representative of all students with SSMI. However, these students, despite their diversity, appeared to benefit from shared story reading. This in itself suggests the potential power of shared storybook interventions combined with the use of AAC and supportive communication strategies. At the same time, it must be noted that the current investigation remains insufficient to clearly demonstrate which factors contributed the most to the changes observed in student behaviours.

Another limitation found in this study was researcher awareness of each study phase during the coding process. To limit potential bias in the future, studies should be designed 
to include random selection of video recordings for coding, with specific study phases unknown to the coders.

\section{Implications for Practice}

Shared storybook reading can serve as a powerful means of promoting communication for students with severe disabilities. As previous research has indicated (Bellon-Harn \& Harn, 2008; Bellon et al., 2000; Browder et al., 2008; Hudson \& Test, 2011; Justice \& Kaderavek, 2002; Kaderavek et al., 2014; Kent-Walsh et al., 2010; Koppenhaver, Erickson, \& Skotko, 2001; Mims et al., 2009; Mims et al., 2012; Musselwhite \& King-DeBaun, 1997; Soto \& Dukhovny, 2008), choosing storybooks that focus their readers' attention on a specific subject depicted on an open page, provide illustrations that clarify the meaning of the words, and contain repeated story lines helps both partners understand each other's communication and further narrows the frame of reference. Those interested in using shared storybook reading as an intervention tool should begin with certain general expectations. Simple alterations can improve the outcome of communication for students with SSMI.

- Anticipate inconsistency-Our research showed that factors often beyond our control, sensory needs, health, and attention to task often hampered students' performance. However, the persistence of the adults in the present study demonstrated that, given time and patience, students can make significant progress.

- Find interesting, age-appropriate books that include repeated lines-Appropriate and appealing reading materials support students' attention to task and learning. Books with repeated lines provide students more frequent opportunities to communicate through AAC or other means using predictable vocabulary.

- Carefully consider the student's current communication repertoire before adding supplemental forms - If the student already has an appropriate and effective means of communicating during shared reading, do not replace it. Rather, consider using AAC to expand the student's communication to meet new challenges.

For students with SSMI, becoming increasingly competent communicators is the first step toward becoming literate. To progress, students must move beyond communication and shared storybook reading to emergent levels of literacy and eventual conventional literacy. While research documents successful communication and literacy instructional programs for students with SSMI, many educators continue to overlook their potential benefits. To narrow the gap between research and practice, researchers should ensure the accessibility of the interventions utilized. Programs should be easy to follow and understand. Readily replicable protocols and reliance upon readily available materials also would encourage educators to put strategies to use in their own classrooms. Perhaps most importantly, educators must understand the definition of literacy and its precursory communication skills for students with SSMI. To accomplish this, researchers need to find ways to encourage teachers to reconsider their views of their students' abilities and needs. Unfortunately, even the best instructional efforts will likely meet with failure unless teachers hold the basic belief that students with SSMI can attain literacy 
starting with precursory reading activities focusing on shared storybook reading and communication.

\section{Implications for Research}

Like those students who participated in the present research, many individuals, for one reason or another, have not been able to develop conventional literacy skills. Research in this area should focus both on reasons for prior failure and on instructional materials and strategies. Through a better understanding of what has been tried, researchers can devise new approaches to instruction. Further, research must carefully investigate reading materials. It is difficult to find interesting, age-appropriate storybooks for older students. Many books developed for typical emergent readers do not relate to the lives of older elementary-aged students, let alone adolescents and adults who struggle to learn to read. As a result, appropriate texts often must be adapted or specially written. Unfortunately, most educators have little extra time to create the volume of books needed by older students engaged in emergent literacy learning.

In conclusion, researchers can promote the literacy of students with SSMI by developing a clear understanding of their needs and using shared story reading with a communication focus as evidence-based practices for later literacy instruction (Browder et al., 2014; Erickson et al., 2009). As the results of this study indicate, students' sensory needs as well as the use of age-appropriate materials, AAC, and supportive communication strategies should be considered when crafting IEP emergent literacy goals that advance their skills to meet future literacy demands, including phonemic awareness, decoding, vocabulary development, and comprehension (Erickson et al, 2009).

\section{References}

Arnold, D. H., Lonigan, C. J., Whitehurst, G. J., \& Epstein, J. N. (1994). Accelerating language development through picture book reading: Replication and extension to a videotape training format. Journal of Educational Psychology, 86(2), 235-243.

Bedrosian, J. L. (1999). Efficacy research issues in AAC: Interactive storybook reading. Augmentative and Alternative Communication, 15(1), 45-55.

Bellon, M. L., \& Ogletree, B. T. (2000). Repeated storybook reading as an instructional method. Intervention in School and Clinic, 36(2), 75-81.

Bellon, M., Ogletree, B., \& Harn, W. (2000). The application of scaffolding within repeated storybook reading as a language intervention for children with autism. Focus on Autism and Other Developmental Disabilities, 15(1), 52-58.

Bellon-Harn, M., \& Harn, W. (2008). Scaffolding strategies during repeated storybook reading: An extension using a voice output communication device. Focus on Autism and Other Developmental Disabilities, 23, 112-124.

Bennett-Brown, N., \& Dunn, W. (2010). Relationship between context and sensory processing in children with autism. American Journal of Occupational Therapy, 64(3), 474-483.

Browder, D. M., Hudson, M. E., \& Wood, L. (2013). Teaching students with moderate intellectual disability who are emergent readers to comprehend passages of text. Exceptionality: A Special Education Journal, 21(4), 191-206. 
Browder, D. M., Lee, A., \& Mims, P. (2011). Using shared stories and individual response modes to promote comprehension and engagement in literacy for students with multiple, severe disabilities. Education and Training in Autism and Developmental Disabilities, 46(3), 339-351.

Browder, D. M., Mims, P. J., Spooner, F., Ahlgrim-Delxell, L., \& Lee, A. (2008). Teaching elementary students with multiple disabilities to participate in shared stories. Research and Practice for Persons with Severe Disabilities, 33(1-2), 3-12.

Browder, D. M., Trela, K., \& Jimenez, B. (2007). Training teachers to follow a task analysis to engage middle school students with moderate and severe developmental disabilities in grade appropriate literature. Focus on Autism and Other Developmental Disabilities, 22(4), 206-219.

Browder, D. M., Wakeman, S. Y., Spooner, F., Ahlgrim-Delzell, L., \& Algozzine, B. (2006). Research on reading instruction for individuals with significant cognitive disabilities. Exceptional Children, 72(4), 392-408.

Browder, D. M., Wood, L., Thompson, J., \& Ribuffo, C. (2014). Evidence-based practices for students with severe disabilities (Document No. IC-3). Retrieved from University of Florida, Collaboration for Effective Educator, Development, Accountability, and Reform Center website: http://ceedar.education.ufl.edu/tools/innovation-configurations/

Chen, M., \& Boggett-Carsjens, J. (2005). Consider sensory processing disorders in the explosive child: Case report and review. Canadian Child and Adolescent Psychiatry Review, 14(2), 44-48.

Crane, L., Goddard, L., \& Pring, L. (2010). Sensory processing in adults with autism spectrum disorder. Research in Autism Spectrum Disorders, 4(4), 746-754. doi:10.1177/1362361309103794

Dunn, W. (2007). Supporting children to participate successfully in everyday life using sensory processing knowledge. Infant \& Young Children, 20(2), 84-101.

Erickson, K. A., Hanser, G., Hatch, P., \& Sanders, E. (2009). Research-based practices for creating access to the general curriculum in reading and literacy for students with significant intellectual disabilities. Monograph prepared for the Council for Chief State School Officers (CCSSO) Assessing Special Education Students (ASES) State Collaborative on Assessment and Student Standards (SCASS). Washington, DC: Council of Chief of State School Officers.

Forts, A. M., \& Luckasson, R. (2011). Reading, writing, and friendship: Adult implications of effective literacy instruction for students with intellectual disability. Research \& Practice for Persons with Severe Disabilities, 36(3), 121-125.

Higginbotham, D. J., \& Bedrosian, J. L. (1995). Subject selection in AAC research: Decision points. Augmentative and Alternative Communication, 11(1), 11-13.

Hochhauser, M., \& Engel-Yeger, B. (2010). Sensory processing abilities and their relation to participation in leisure activities among children with high-functioning autism spectrum disorder (HFASD). Research in Autism Spectrum Disorders, 4(4), 746-754.

Hudson, M. E., \& Test, D. W. (2011). Evaluating the evidence base of shared story reading to promote literacy for students with extensive support needs. Research \& Practice for Persons with Severe Disabilities, 36(1), 34-45.

Justice, L. M., \& Kaderavek, J. (2002). Using shared storybook reading to promote emergent literacy. Teaching Exceptional Children, 34(4), 8-13.

Kaderavek, J. N., Pentimonti, J. M., Justice, L. M. (2014). Children with communication impairments: Caregivers' and teachers' shared book-reading quality and children's level of engagement. Child Language Teaching and Therapy, 30(3), 289-302.

Kent-Walsh, J., Binger, C., \& Hasham, Z. (2010). Effects of parent instruction on the symbolic communication of children using augmentative and alternative communication during storybook reading. American Journal of Speech-Language Pathology, 19, 97-107. 
Kliewer, C. (2008). Joining the literacy flow: Fostering symbol and written language learning in young children with significant developmental disabilities through the four currents of literacy. Research and Practice for Persons with Severe Disabilities, 33(3), 103-121.

Kliewer, C., \& Biklen, D. (2001). School's not really a place for reading: A research synthesis of the literate lives of students with severe disabilities. Journal of the Association for Persons with Severe Handicaps, 26(1), 1-12.

Kliewer, C., Biklen, D., \& Kasa-Hendrickson, C. (2006), Who may be literate?: Disability and resistance to the cultural denial of competence. American Educational Research Journal, 43(2), 163-192.

Koppenhaver, D. A. (2000). Literacy in AAC: What should be written on the envelope we push? Augmentative and Alternative Communication, 16(4), 270-279.

Koppenhaver, D. A., Erickson, K. A., Harris, B., McLellan, J., Skotko, B. G., \& Newton, R. A. (2001). Storybook-based communication intervention for girls with Rett syndrome and their mothers. Disability and Rehabilitation, 23(3-4), 149-159.

Koppenhaver, D. A., Erickson, K. A., \& Skotko, B. G. (2001). Supporting communication of girls with Rett syndrome and their mothers in storybook reading. International Journal of Disability, Development and Education, 48(4), 395-410.

Koppenhaver, D. A., \& Pierce, P. L. (1994). Written language development research in AAC. Paper presented at the ISAAC Research Symposium, Kerkrade, The Netherlands.

Kranowitz, C. S. (2003). The out-of-sync child has fun. New York, NY: Perigree Books.

Leekam, S. R., Nieto, C., Libby, S. J., Wing, L., Gould, J. (2007). Describing the sensory abnormalities of children and adults with autism. Journal of Autism and Developmental Disabilities, 37, 894-910. doi10.1007/s10803-006-0218-7

Liboiron, N., \& Soto, G. (2006). Shared storybook reading with a student who uses alternative and augmentative communication: A description of scaffolding practices. Child Language Teaching and Therapy, 22(1), 69-95.

Light, J., Binger, C., \& Kelford Smith, A. (1994). Story reading interactions between preschoolers who use AAC and their mothers. Augmentative and Alternative Communication, 10(4), 255268.

Light, J. C., \& Kent-Walsh, J. (2003). Fostering emergent literacy for children who require AAC. The ASHA Leader, 8(4-5), 28-29.

McDonnell, S. A., Friel-Patti, S., Rollins, P. R. (2003). Patterns of change in maternal-child discourse behaviors across repeated storybook readings. Applied Psycholinguistics, 24, 323-341. doi:10.1017.S014271640300171

Mims, P. J., Browder, D. M., Baker, J. N., Lee, A., \& Spooner, F. (2009). Increasing comprehension of students with significant intellectual disabilities and visual impairments during shared reading. Education and Training in Developmental Disabilities, 44(3), 409-420.

Mims, P. J., Hudson, M. E., \& Browder, D. M. (2012). Using read-louds of grade-level biographies and systematic prompting to promote comprehension for students with moderate and severe developmental disabilities. Focus on Autism and Other Developmental Disabilities, 27(2), doi: $10.1177 / 1088357612446859$

Mirenda, P. (2003). He's not really a reader...: Perspectives on supporting literacy development in individuals with autism. Topics in Language Disorders, 23(4), 271-282.

Morgan, M. F., Moni, K. B. (2008). Meeting the challenge of limited literacy resources for adolescents and adults with intellectual disabilities. British Journal of Special Education, $35(2), 92-101$. 
Musselwhite, C. R., \& King-DeBaun, P. (1997). Emergent literacy success: Merging technology and whole language for students with disabilities. Park City, UT: Creative Communicating.

National Early Literacy Panel. (2008). Developing early literacy: Report of the National Early Literacy Panel. Washington, DC: National Institute for Literacy.

Ogletree, B. T., Bruce, S. M., Finch, A., Fahey, R., \& McLean, L. (2011). Recommended communication-based interventions for individuals with severe intellectual disabilities. Communication Disorders Quarterly, 32(3), 164-175. doi:10.1177/1525740109348791

Olson, L. J., \& Moulton, H. J., (2004). Occupational therapists' reported experiences using weighted vests with children with specific developmental disorders. Occupational Therapy International, 11(1), 52-66.

Ruppar, A., Dymond, S. K., \& Gaffney, J. S. (2011). Teachers' perspectives on literacy instruction for students with severe disabilities who use augmentative and alternative communication. Research and Practice for Persons with Severe Disabilities. 36, 100-111.

Ryndak, D., Morrison, A., \& Sommerstein, L. (1999). Literacy before and after inclusion in general education settings: A case study. Journal of the Association for Persons with Severe Handicaps, 24(1), 5-22.

Shurr, J., \& Taber-Doughty, T. (2012). Increasing comprehension for middle school students with moderate intellectual disabilities on age-appropriate texts. Education and Training in Autism and Developmental Disabilities, 47(3), 359-372.

Skotko, B. G., Koppenhaver, D. A., \& Erickson, K. A. (2003a). Definitions of child codes. Retrieved September 24, 2004, from the University of North Carolina Chapel Hill, The Center for Literacy and Disability Studies web site: www.med.unc.edu/ahs/clds/index.html

Skotko, B. G., Koppenhaver, D. A., \& Erickson, K. A. (2003b). Definitions of parent codes. Retrieved September 24, 2004, from the University of North Carolina Chapel Hill, The Center for Literacy and Disability Studies web site: www.med.unc.edu/ahs/clds/index.html

Skotko, B. G., Koppenhaver, D. A., \& Erickson, K. A. (2004). Parent reading behaviors and communication outcomes in girls with Rett syndrome. Exceptional Children, 70, 145-166.

Soto, G., \& Dukhovny, E. (2008). The effect of shared book reading on the acquisition of expressive vocabulary of a 7 year old who uses AAC. Seminars in Speech and Language, 29, 133-145.

Sturm, J. M. (2003). Writing and AAC. The ASHA Leader, 8(8-9), 26-27.

Sturm, J. M., \& Clendon, S. A. (2004). Augmentative and alternative communication, language, and literacy: Fostering the relationship. Topics in Language Disorders, 24(1), 76-91.

Tomchek, S., \& Dunn, W. (2007). Sensory processing in children with and without autism: A comparative study utilizing the short sensory profile. American Journal of Occupational Therapy, 61(2), 190-200.

\section{Authors' Note}

Correspondence concerning this article should be addressed to Denise Clark, University of Wisconsin Oshkosh, 800 Algoma Blvd., Oshkosh, WI, 54901, USA. Email: clarkd@uwosh.edu 